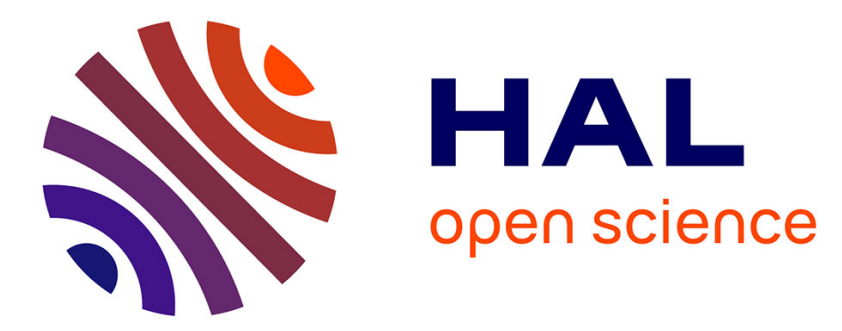

\title{
Rheological and metallurgical discussion of superplastic behaviour
}

\author{
M. Suery, B. Baudelet
}

\section{To cite this version:}

M. Suery, B. Baudelet. Rheological and metallurgical discussion of superplastic behaviour. Revue de Physique Appliquée, 1978, 13 (2), pp.53-66. 10.1051/rphysap:0197800130205300 . jpa-00244422

\section{HAL Id: jpa-00244422 https://hal.science/jpa-00244422}

Submitted on 1 Jan 1978

HAL is a multi-disciplinary open access archive for the deposit and dissemination of scientific research documents, whether they are published or not. The documents may come from teaching and research institutions in France or abroad, or from public or private research centers.
L'archive ouverte pluridisciplinaire HAL, est destinée au dépôt et à la diffusion de documents scientifiques de niveau recherche, publiés ou non, émanant des établissements d'enseignement et de recherche français ou étrangers, des laboratoires publics ou privés. 


\title{
REVUE DE PHYSIQUE APPLIQUÉE
}

\author{
Classification
}

Physics Abstracts

$62.20 \mathrm{~F}$

\section{RHEOLOGICAL AND METALLURGICAL DISCUSSION OF SUPERPLASTIC BEHAVIOUR}

\author{
M. SUERY and B. BAUDELET \\ Laboratoire de Physique et de Technologie des Matériaux (*) \\ Université de Metz, 57000 Metz, France
}

(Reçu le 19 octobre 1977, accepté le 21 novembre 1977)

\begin{abstract}
Résumé. - Une analyse de l'évolution de la structure des matériaux superplastiques au cours de la déformation montre que celle-ci tend à devenir équiaxe et à présenter du grossissement. Cette évolution a une influence sur la loi de comportement : taux d'écrouissage apparent, allure sigmoïdale de la courbe $\log \sigma-\log \dot{\varepsilon}$, valeur faible de l'énergie d'activation apparente dans le domaine des vitesses intermédiaires. Il est montré qu'en tenant compte de cette évolution, il est possible d'interpréter le comportement observé. L'analyse présentée permet de mettre en évidence une loi de comportement à caractère métallurgique puisqu'elle tient compte de la structure en évolution. Par opposition, la loi généralement proposée est rhéologique et ne peut être utilisée que dans une approche strictement mécanique. Une analogie hydrodynamique à l'écoulement superplastique est ensuite présentée : elle montre que ce comportement apparaît d'une part lorsque la phase la plus dure n'est pas continue, et d'autre part lorsque la phase la plus ductile a un libre parcours moyen limité à quelques microns ; elle explique les évolutions de texture différentes pour les deux phases et rend compte du glissement observé au niveau des interfaces. De plus, cette étude permet de suggérer qu'un comportement superplastique à valeur élevée du coefficient $m$ peut être observé, bien que des allongements importants ne puissent pas apparaître dans le cas où le matériau présente de l'endommagement résultant d'un glissement difficile au niveau des interfaces.
\end{abstract}

\begin{abstract}
The analysis of the deformation of superplastic materials shows that the structure tends to evolve towards an equiaxed state and to undergo grain growth. This behaviour influences the constitutive equations : apparent strain-hardening, sigmoïdal variation of the Log stress Log strain rate curve, low apparent activation energy values at intermediate strain rates. This deformation behaviour can be explained when the structural change is taken into account. The analysis described leads to a constitutive equation which presents a metallurgical basis since it takes into account the structural changes. By contrast, the generally proposed relationship is rheological and can be used only within a strictly mechanical approach. An hydrodynamic analogy of superplastic flow is then presented. It shows that superplasticity occurs, on the one hand when the hardest phase is not continuous, and on the other hand when the most ductile phase has a mean free path no greater than a few microns. The analogy also demonstrates that the textural evolution is different for the two phases and accounts for the observed interface sliding. Furthermore, this study suggests that superplastic behaviour with elevated values of the coefficient $m$ can be observed, although large elongations cannot be obtained in cases where the material undergoes cavitation resulting from difficulties in interface sliding.
\end{abstract}

1. Introduction. - Superplastic behaviour occurs in metallic materials, usually alloys, in which a fine grained equiaxed structure can be obtained. This structure may be achieved by heavy hot working followed by recrystallization and is subsequently stabilized through composition and phase distribution control. Superplastic materials are generally eutectic and eutectoid alloys or alloys having a microduplex structure, although preponderantly single phase materials have also been observed to behave in this way.

(*) Laboratoire associé au C. N. R. S., nº 155.
Many studies have been carried out on these materials, and nearly all the experimental results show a number of common characteristics, the most important being the following :

- The stress is strongly strain rate dependent. The variation of the stress $\sigma$ with the strain rate $\dot{\varepsilon}$ on a Log$\log$ plot (subsequently referred to a $\log \sigma-\log \dot{\varepsilon}$ curve) appears generally sigmoidal and can be divided into three characteristic regions for samples of identical initial microstructure. The strain rate sensitivity $m$ is higher at intermediate strain rates (region II). Low or high strain rates (regions I and III respectively) lead 
to lower $m$ values. However, a region in which $m$ is close to unity has been observed at very low strain rates, particularly in the $\mathrm{Zn}-\mathrm{Al}$ eutectoid alloy [1], but will not be considered further as it is likely to be associated with vacancy-controlled creep behaviour [2-4].

- Superplastic behaviour occurs at high temperatures (above $0.5 T \mathrm{~m}$, where $T \mathrm{~m}$ is the absolute melting temperature). An increase in temperature tends to increase $m$ and to shift its maximum value towards higher strain rates.

- The constitutive equation depends upon the initial grain size of the material ; a decrease in grain size decreases the flow stress, except in region III, and shifts the maximum value of $m$ towards higher strain rates.

Various relationships have been proposed to rationalize this behaviour. In the first part, we shall examine these relations, restricting the structure parameter to its value prior to deformation. In the second part, we shall consider how these relationships are modified when the structure parameter is no longer constant but changes with the structure during deformation. Finally, the particular characteristics of two-phase materials will be discussed, and an hydrodynamic analogy of superplastic behaviour will be proposed.

2. Constitutive equation based on the initial structure. - The parameter which describes this structure is generally obtained from metallographic sections by a linear intercept method [5]. In preponderantly singlephase materials, it is equal to the grain size ; for twophase materials with approximately equal volume fractions, it corresponds to the average size of the phases. This quantity will be subsequently referred to as $D_{\mathbf{i}}$.

In order to take into account the sigmoidal variation of the $\log \sigma-\log \dot{\varepsilon}$ curve, several regions have been defined for which various constitutive equations have been established. Such an analysis is difficult and somewhat arbitrary, particularly when the linear part (region II) is ill-defined. On the other hand in region III, all the experimental results show that superplastic behaviour is similar to that of conventional materials under hot working conditions [6] and we shall not dwell further on it. In view of the experimental results, three types of relationships have been proposed :

$$
\dot{\varepsilon}=A \frac{\sigma^{1 / m_{1}}}{D_{\mathrm{i}}^{a}} \exp \left(-\frac{Q}{k T}\right)
$$

where $m_{1}, Q$ and $a$ are constant

$$
\dot{\varepsilon}=B \frac{\sigma^{1 / m_{2}}}{D_{i}^{a}} \exp \left(-\frac{Q(\sigma)}{k T}\right)
$$

where $Q(\sigma)$ is a stress-dependent activation energy.

$$
\dot{\varepsilon}=C \frac{\left(\sigma-\sigma_{0}\right)^{1 / m_{3}}}{D_{\mathrm{i}}^{a}} \exp \left(-\frac{Q}{k T}\right)
$$

where $\sigma_{0}$ is a threshold stress below which the strain rate is zero.

From these relationships and by combining them, it is possible to adjust the $\log \sigma-\log \dot{\varepsilon}$ curve either by assuming two different mechanisms in regions I and II or by assuming only one mechanism given by equation (3).

2.1 DifFERENT DEFORMATION MECHANiSMS. - This hypothesis is supported by a few observations which have suggested a distinct behaviour in region $\mathrm{I}$ : less grain boundary sliding, denuded zones near grain boundaries and grain elongation [6]. Two types of analysis may then be envisaged :

- Regions I and II are assumed to be straight lines on $\log \sigma-\log \dot{\varepsilon}$ plots ; type (1) relationships then allow a description of this behaviour. Under these conditions, in region II, $Q$ is usually close to the grain boundary diffusion activation energy [6] and a lies between 2 and 4 [7]. According to this approach $m_{1}$, which appears in equation (1), is at least equal to the maximum slope of the $\log \sigma-\log \dot{\varepsilon}$ curve. Values lying between 0.5 and 0.8 are typical. In region $\mathrm{I}, Q$ is generally closer to the bulk diffusion activation energy $[6,8,9]$. However, a is poorly known although values close to 2.5 have been obtained for the $\mathrm{Zn}-\mathrm{Al}$ eutectoid alloy $[1,10]$ and values of 0.2 to 0.3 can be attributed to $m_{1}$.

- A continuous variation of the strain rate sensitivity coefficient with strain rate, together with high activation energies at low stresses have led to the assumption of the existence of a thermally activated mechanism at low stresses $[11,12]$. Thus, activation volumes at the transition between regions I and II have been computed for several alloys from the relationship $V=2 n k T / \sigma$ [13]. The values obtained are of the order of $1000 b^{3}$ [12]. Under these conditions, region II is described by a type (1) relationship where the parameters have values of the order given earlier, whereas region I can be analyzed by a type (2) relationship in which $m_{2}$ is close to unity.

2.2 Single MEChanism. - The existence of a threshold stress $\sigma_{0}$ has been suggested by several investigators to explain the transition between region II and region I, as well as low strain rate sensitivity values in the latter region [14-16]. If one assumes a Binghamtype flow, $\dot{\varepsilon}$ proportional to $\left(\sigma-\sigma_{0}\right)$, for the superplastic region or, more generally, if it is assumed that $\dot{\varepsilon}$ is a function of $\left(\sigma-\sigma_{0}\right)$, the slope of the $\log \sigma-\log \dot{\varepsilon}$ curve ought to decrease asymptotically towards zero when the applied stress tends toward $\sigma_{0}$. Values of $\sigma_{0}$ at zero strain rates have been obtained by extrapolating the stress in $\mathrm{Al}-\mathrm{Cu}$ [9], $\mathrm{Mg}-\mathrm{Zn}-\mathrm{Zr}$ [17] and $\mathrm{Pb}-\mathrm{Sn}$ [18, 19] alloys. Under these conditions, region II appears as a transition stage $[20,21]$ between low strain rate sensitivity regions, one arising from the threshold stress $\sigma_{0}$, the other being the hot working region III. This approach leads to maximum values of the strain rate 
sensitivity coefficient $m_{\max }$ which depend upon the extent of the transition region; the higher the stress variation, the higher the $m_{\max }$ value [22].

The analysis carried out when the initial structure is considered as a parameter shows that the sigmoidal aspect of the $\log \sigma-\log \dot{\varepsilon}$ curves can be explained from three main forms of the Arrhenius equation. However, other equations or combinations of these can be used to fit the experimental results [23].

3. Constitutive equations based on the structure during deformation. - The constitutive equations described earlier were established using the initial size of the grains or phases as a structure parameter. These equations may provide the basis for a metallurgical model as long as the structure does not evolve during deformation. However, if it changes in the process, these equations can no longer be used for this purpose but nevertheless remain valid in a strictly rheological approach. A few studies have indeed shown structural variations during deformation for many superplastic alloys. We shall therefore firstly recall the structure changes before we introduce the structure parameter or parameters characteristic of the instantaneous deformation condition, into the constitutive equation. The description of the evolution in the early stages of deformation in a transient region will be distinguished from that during the pseudo-steady state region which occurs later. The real behaviour is somewhat more complex as both evolutions occur simultaneously to some extent.

3.1 Transient Region. - Superplastic alloys are generally two-phase materials for which several types of structure can be observed. The phases are generally of different ductility. We shall call B the less ductile phase, although it is difficult to distinguish in some alloys ( $\mathrm{Pb}-\mathrm{Sn}, \mathrm{Pb}-\mathrm{Cd}, \mathrm{Sn}-\mathrm{Bi}, \mathrm{Bi}-\mathrm{In}$...). These structures are as follows :

Structure $(a)$ : The B-phase appears as precipitates along the boundaries of the A-grains (Fig. 1a).

Structure (b) : The B-phase is constituted of grains or groups of grains dispersed in the A-phase (Fig. 1b).

Structure (c) : The A-phase takes the form of precipitates located on the boundaries of the B-phase (Fig. 1c).

Structure $(d)$ : The A-phase now appears in the form of grains or groups of grains dispersed in the B-phase (Fig. 1d).

Structure (e) : Both phases are continuous (Fig. 1e).

Such a condition occurs most frequently in as-cast alloys.

Table I gives for most superplastic alloys, the nature of the phases A and B, together with the type of structure observed. It can be seen readily that all superplastic alloys, for which the ductilities of the two phases are quite different, show structures of the types (a) or (b), i. e. of a less deformable phase dispersed in a ductile matrix. It is worth noting that in all cases the

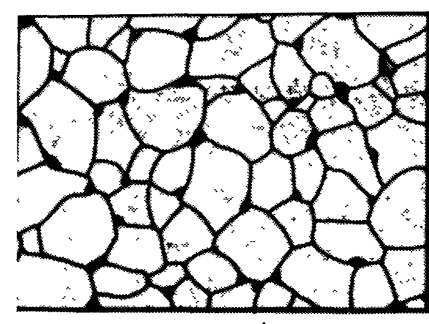

'structure (a)

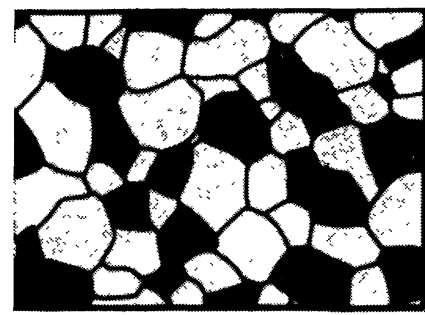

structure (b)

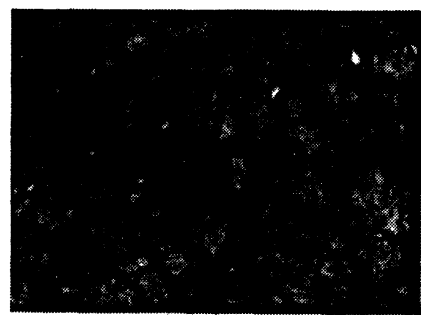

structure (c)

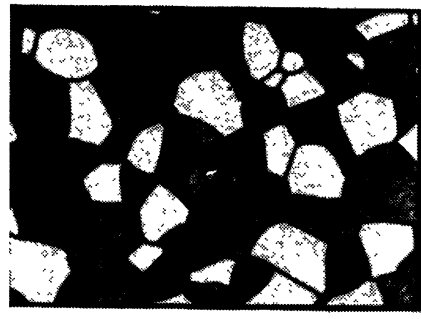

structure (d)

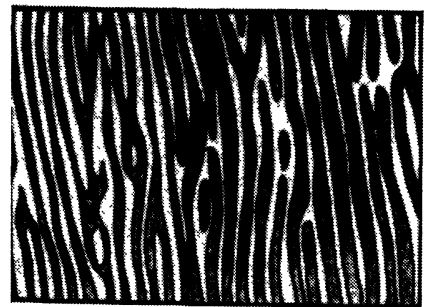

structure (e)

Fig. 1. - Theoretical structures which could be observed in two-phase alloys. Phase A is light, phase B dark.

mean free path in the A-phase is small and of the order of a few microns.

This fine grained structure, often obtained by extrusion or rolling, appears generally elongated along the direction of deformation. In alloys of type (a), this elongation can be characterized by the ratio of the longitudinal to transverse dimensions $\left(D_{\|} / D_{\perp}\right)$ of the grains of the A-phase as measured on sections taken parallel to the extrusion or rolling direction. On (b)type structures, phase B is constituted of grains preferentially connected to other grains of the same phase along the working direction. Grain boundaries of the B-phase are revealed by the cusps at the A-B interfaces [24]. The elongated character of the structure can be described by the ratio of the longitudinal to 
TABLE I

Common superplastic alloys, showing the phases present and the type of structure observed (see Fig. 1)

\begin{tabular}{|c|c|c|c|}
\hline Alloy & Phase A & Phase B & Structure \\
\hline $\mathrm{Al}-\mathrm{Cu}$ eutect. & $\mathrm{Al} \alpha$ & $\mathrm{Al}_{2} \mathrm{Cu}$ & (b) \\
\hline $\mathrm{Al}-17 \mathrm{Cu}$ & $\mathrm{Al} \alpha$ & $\mathrm{Al}_{2} \mathrm{Cu}$ & (a) $\rightarrow$ (b) \\
\hline $\mathrm{Al}-33 \mathrm{Cu}-7 \mathrm{Mg}$ & $\mathrm{Al} \alpha$ & $\begin{array}{c}\mathrm{CuAl}_{2} \\
\mathrm{CuMgAl}_{2}\end{array}$ & (b) \\
\hline $\mathrm{Al}-25 \mathrm{Cu}-11 \mathrm{Mg}$ & $\mathrm{Al} \alpha$ & $\mathrm{CuMgAl}_{2}$ & (b) \\
\hline Al-Si eutect. & Al & $\mathrm{Si}$ & (a) $\rightarrow$ (b) \\
\hline Al-6 Zn-3 Mg & $\mathrm{Al} \alpha$ & & (a) \\
\hline $\mathrm{Al}-\mathrm{Zn}-\mathrm{Mg}-\mathrm{Zr}$ & $\mathrm{Al} \alpha$ & & (a) \\
\hline Cd-Zn eutect. & $\mathrm{Cd}$ & $\mathrm{Zn}$ & (b) \\
\hline Co-10 Al & $\operatorname{Co} \alpha$ & CoAl & (b) \\
\hline $\mathrm{Cu}-9$ to $10 \mathrm{Al}$ & $\mathrm{CuAl} \beta$ & $\mathrm{CuAl} \alpha$ & (b) \\
\hline $\mathrm{Cu}-5$ to $7 \mathrm{P}$ & $\mathrm{Cu} \alpha$ & $\mathrm{Cu}_{3} \mathrm{P}$ & (b) \\
\hline $\mathrm{Cu}-40 \mathrm{Zn}$ & $\mathrm{CuZn} \beta$ & $\operatorname{CuZn} \alpha$ & (b) \\
\hline $\mathrm{Cu}-\mathrm{Ag}$ eutect. & $\operatorname{Ag} \alpha$ & $\mathrm{Cu} \alpha$ & (b) \\
\hline $\mathrm{Cd}-27 \mathrm{Zn}$ & $\mathrm{Cd}$ & $\mathrm{Zn}$ & (b) \\
\hline Steels & $\alpha$ & $\gamma$ & (b) \\
\hline Stainl. Steels & & & \\
\hline $\mathrm{Fe}-25 \mathrm{Cr}-6 \mathrm{Ni}$ & $\alpha$ & $\gamma$ & (b) \\
\hline $\begin{array}{l}\mathrm{Cu}-15 \mathrm{Ni}-38 \mathrm{Zn} \\
\mathrm{Mg}-0.5 \mathrm{Zr}\end{array}$ & $\alpha$ & $\beta$ & (b) $\rightarrow$ (a) \\
\hline $\mathrm{Mg}-6 \mathrm{Zn}-0.5 \mathrm{Zr}$ & $\mathrm{Mg}$ & $\mathrm{Zr}$ & (a) \\
\hline Mg-Al eutect. & $\gamma$ & $\delta(\mathrm{Mg})$ & (b) \\
\hline $\mathrm{Ni}-39 \mathrm{Cr}-8 \mathrm{Fe}$ & $\gamma$ & $\mathrm{Cr} \alpha$ & (b) \\
\hline $\mathrm{Sn}-5 \mathrm{Bi}$ & & & \\
\hline $\mathrm{Sn}-1 \mathrm{Bi}$ & Sn & $\mathrm{Bi}$ & (a) \\
\hline Sn-Bi eutect. & $\mathrm{Sn}$ & $\mathrm{Bi}$ & (b) \\
\hline Zn-Al eutectic & $\mathrm{Zn}$ & $\mathrm{Al} \alpha_{1}$ & (b) \\
\hline Zn-Al eutectoid & $\mathrm{Zn}$ & $\mathrm{Al} \alpha$ & (b) \\
\hline $\mathrm{Zn}-0.4 \mathrm{Al}$ & $\mathrm{Zn}$ & $\mathrm{Al} \alpha$ & (a) \\
\hline $\mathrm{Zn}-\mathrm{ZnO}{ }_{2}$ & $\mathrm{Zn}$ & $\mathrm{ZnO}_{2}$ & (a) \\
\hline $\mathrm{Zn}-\mathrm{W}$ & $\mathrm{Zn}$ & W & (a) \\
\hline $\mathrm{Zn}-0.1 \mathrm{Ni}-0.04 \mathrm{Mg}$ & $\mathrm{Zn}$ & $\delta$ & (a) \\
\hline
\end{tabular}

transverse dimensions of the B-phases. On extruded $60 / 40$ brass, the $D_{\|} / D_{\perp}$ ratio was found to be 1.5 [25]. A higher value of about 1.8 has been observed in an eutectic Al-Cu alloy [26].

Observations have shown that the structure changes during the early stages of deformation. In the first case, the $D_{\|} / D_{\perp}$ ratio varies from alloy to alloy. For a $\mathrm{Zn} 1 \% \mathrm{Al}$ alloy for instance, the $D_{\|} / D_{\perp}$ ratio increases with deformation and at a rate which decreases with strain rate [27]. In contrast, for a $\mathrm{Cd}-\mathrm{Pb}$ alloy, the $D_{\|} / D_{\perp}$ ratio appears to increase at the surface, while it remains nearly constant in the bulk of the sample [28]. On alloys displaying a (b)-type structure, all the observations show a tendency for the B-phase grains to separate and to become rounder $[25,26,29,30]$. Brass, for example, shows a maximum in the $D_{\|} / D_{\perp}$ ratio in the early stages of deformation [25], followed by an evolution towards a nearly equiaxed structure, leading to a decrease of the $D_{\|} / D_{\perp}$ ratio towards 1 (Fig. 2). These changes occur without any apparent increase

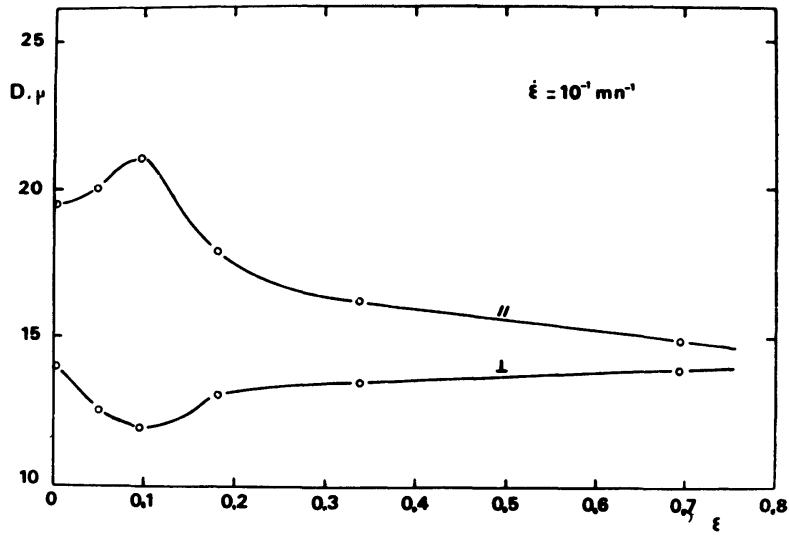

Fig. 2. - The longitudinal and transverse dimensions of the B-phase as a function of the true strain at constant strain rate for $60 / 40$ brass. After [25].

in the number of grains of the B-phase [31]. This transition to an equiaxed structure takes place fairly early during deformation : before 20 to $30 \%$ elongation for the 60/40 brass (25) and for the Cu-P alloy [32], before $40 \%$ for $\mathrm{Cu}-\mathrm{Zn}-\mathrm{Fe}$ alloy [33] and before $80 \%$ for IN-744 [34]. These values increase with the strain rate [32]. For (e)-type structures, it has been shown for the Al-Cu eutectic alloy $[35,36]$ that under favourable strain rate and temperature conditions, the as-cast structure could be split, the $\mathrm{Al}_{2} \mathrm{Cu}$ phase becoming isolated and with an overall equiaxed structure. Similar observations were made on a welded Ti-base alloy [37], but it must be pointed out that this behaviour is not common [22].

There are only a few studies which have investigated the effect of this structural evolution on the mechanical behaviour:

- In (b)-type structures, the transition towards the equiaxed condition is associated with :

- A higher stress, whose maximum corresponds roughly to the maximum of the $D_{\|} / D_{\perp}$ ratio [25]. It must be noted that this maximum is absent if the alloy has initially an approximately equiaxed structure. In TA6V, for example, the flow stress is three times that of the same alloy in the equiaxed condition [38].

- Values of the rheological coefficient $m$ which increase from about $0.3-0.4$ to values often close to 0.5 (Fig. 3). Such an effect has been observed for several alloys : stainless steels [30], IN-744 and Fe-Cu [34], steels [39].

We shall propose later an interpretation of these results.

- In (e)-type structures, the transient region can be equally associated with a higher stress, but with a much higher ratio between the maximum stress and that for the equiaxed state, about 20 in the $\mathrm{Al}-\mathrm{Cu}$ alloy [36]. Additionally, it is associated with an increase in the values of the rheological coefficient $m$ from a lower limit close to 0.2 to the values characteristic of the 


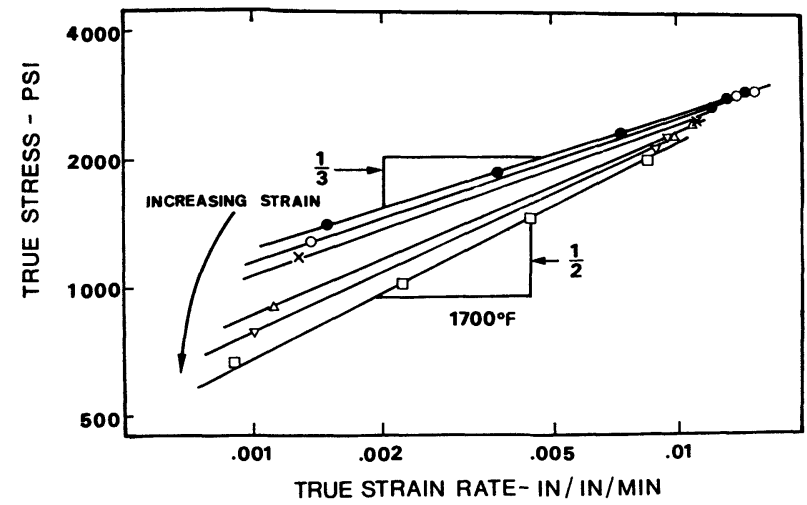

FIG. 3. - The change in the Log stress-Log strain rate curve with increasing strain for a sample of IN-744 having an originally elongated phase structure. After [34].

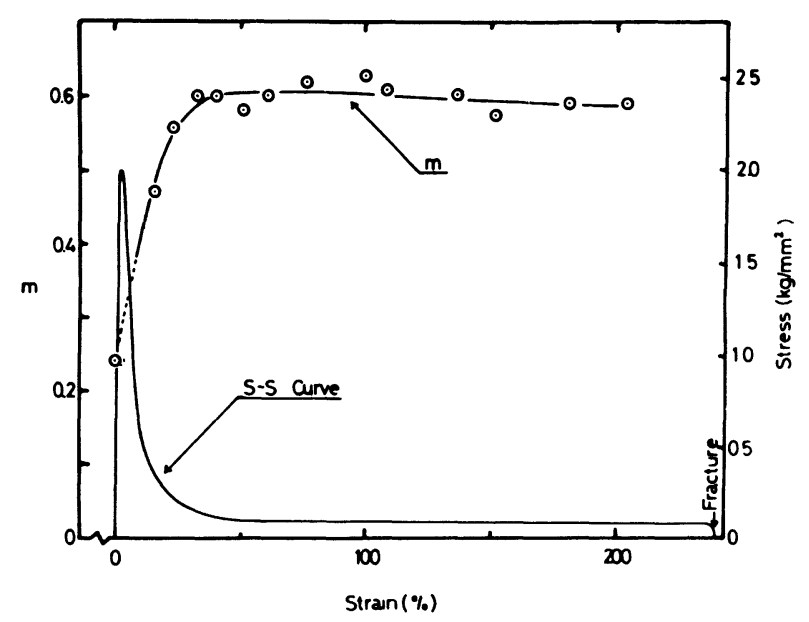

FIG. 4. - Stress and strain rate sensitivity index $m$ against strain for a cast specimen of $\mathrm{Al}-\mathrm{Cu}$ eutectic deformed at $520^{\circ} \mathrm{C}$ with an initial strain rate of $2.3 \times 10^{-4} \mathrm{~s}^{-1}$. After [36]

superplastic condition, i. e. 0.6 in the equiaxed $\mathrm{Al}-\mathrm{Cu}$ alloy [36]. These results are shown in figure 4. This structural change requires the break up of connected phases and it appears likely that it takes place through a plastic deformation mechanism involving subgrains, although there is no microstructural study to support this hypothesis. At a given strain rate, the stress should then be close to that $\sigma_{\text {III }}$ corresponding to the deformation behaviour in domain III. The stress should be higher than the value $\sigma_{\mathrm{II}}$ corresponding to the deformation behaviour in region II at the same strain rate (Fig. 5). Similarly, the measured $m$ value should be characteristic or region III.

All these observations show, for the evolution of a structure towards the equiaxed condition that :

- About $30 \%$ elongation is required to establish a pseudo-steady-state region with an approximately equiaxed structure.

- A higher stress is usually generated in the early stages of deformation.

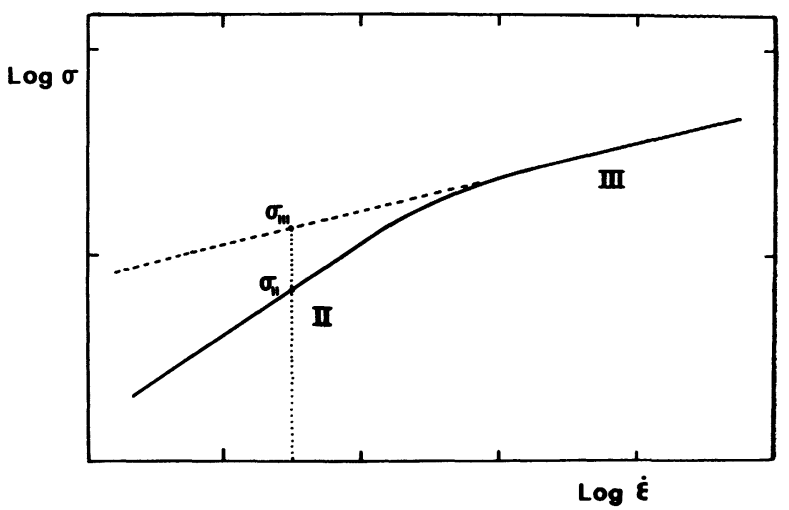

FIG. 5. - Theoretical variation of the stress with strain rate. This shows at any given strain rate, the difference between the stresses corresponding to deformation in region III and in region II.

- The value of the rheological coefficient $m$ is lower at the onset of deformation than in the steady state region, and may be as low as that in stage III.

From these important conclusions, it can be inferred that the constitutive equation obtained below about $30 \%$ elongation is not characteristic of the pseudosteady-state region. This could then partly explain stage I which is generally observed on the $\log \sigma-$ Log $\dot{\varepsilon}$ curve. This plot can be obtained in two different ways :

- Either on a single specimen by changing the strain rate in increasing or decreasing jumps [40], in which case the stress is determined at different strains.

- Or on several samples of identical initial structure strained at different rates. The $\log \sigma-\log \dot{\varepsilon}$ curve is then plotted for a small given strain, in view of the very low strain rates that must be obtained.

In the first case, and for increasing jumps in the strain rate, the strains at the onset of the test are low and remain within the transient region. The stress is then higher than it would be at a similar strain rate under pseudo-steady-state conditions. On a $\log \sigma-\log \dot{\varepsilon}$ plot, the stresses at low strain rates therefore appear higher, leading to lower apparent slopes. Such behaviour has been observed for a $\mathrm{Pb}-\mathrm{Sn}$ alloy and was attributed to a threshold stress [18]. However, if the strain rate changes in decreasing steps then, at the highest rates, the specimen may be strained beyond the transient region. At the lower strain rates, the stress can then be expected to be characteristic of approximately equiaxed conditions as long as 1) asperities do not reform at low strain rates and 2) no other structural evolution takes place (see the following section).

The same problems as before are experienced when determining the strain rate dependence of the stress from different samples. In order to study the constitutive equation in the superplastic condition, it therefore appears necessary to give an identical prestrain to all 
the samples in order to pass beyond the transient region.

3.2 Pseudo-steady-STate Region. - The deformation in the superplastic region takes place at elevated temperatures and as a result, grain or phase coarsening often occurs. Many investigators have been aware of this $[30,33,41-50]$ but few quantitative studies have been carried out $[25,26,32,36,51,52]$. Grain growth displays several characteristic features :

- It is enhanced by deformation. The grain size of a superplastically deformed sample is larger after deformation than only after annealing at the same temperature for the same time. Grain growth was studied on the $\mathrm{Sn}-1 \% \mathrm{Bi}$ alloy and was attributed to a high rate of vacancy formation at the grain boundaries during superplastic flow [51]. For alloys with an eutectic point, the tendancy for grain growth becomes greater when the composition deviates further from the eutectic composition [36]. In microduplex alloys, it appears that equal volume fractions of the phases minimize grain growth [53].

- The growth increases with strain at any given strain rate. This influence can be characterized by the parameter

$$
\left(\frac{\delta \log D}{\delta \varepsilon}\right)_{\dot{\varepsilon}, T}=f_{\dot{\varepsilon}, T} .
$$

Table II displays the values of this parameter, computed from published data on superplastic alloys [25, $26,32,51]$ for various strain rates. Also shown are the theoretical values obtained from the $\mathrm{Sn}-1 \% \mathrm{Bi}$, using the Clark and Alden model [51].

- At any given strain, the growth is greatest for the lowest strain rates. Table II also gives computed values of

$$
\left(\frac{\delta \log D}{\delta \log \dot{\varepsilon}}\right)_{\varepsilon, T}=g_{\varepsilon, T},
$$

a parameter which characterizes this effect. This parameter decreases towards zero with increasing strain rate.

- Grain growth increases with temperature. This variation is poorly known owing to the lack of experimental results. In the following we shall use the negative quantity $h_{\varepsilon}$; defined as

$$
\left(\frac{\delta \operatorname{Ln} D}{\delta \frac{1}{T}}\right)_{\varepsilon, \dot{\varepsilon}}=\frac{h_{\varepsilon, \dot{\varepsilon}}}{k},
$$

$k$ being Boltzmann's constant.

In general terms, the grain size results from the thermomechanical history and the parameters $f_{\dot{\varepsilon}, \boldsymbol{T}}$ and $g_{\varepsilon, T}$ have been determined for a specific deformation path. Hence they are not partial derivatives of a total differential. Such a situation does not occur in dislocation controlled creep, where the size of the subgrains depends only on the applied stress during steady-state deformation [54]. It is for this reason that, for the deformation of superplastic materials, the region after the transient stage is called pseudo-steadystate.

Experimental results indicate therefore large variations in the size of the grains or phases with strain, strain rate and probably with temperature. On the other hand, rheological equations of the type (1), (2), (3) show the marked influence of the initial size of the grains or phases. There is no indication beforehand that the

\section{TABLE II}

\begin{tabular}{|c|c|c|c|c|c|c|c|c|c|c|c|c|c|c|}
\hline $\begin{array}{c}\text { Alloy } \\
\text { Température }\end{array}$ & $\underset{\min ^{-1}}{\stackrel{\bullet}{\varepsilon}}$ & $\varepsilon_{1}$ & $\varepsilon_{2}$ & $\begin{array}{c}D_{1} \\
\mu\end{array}$ & $\begin{array}{c}D_{2} \\
\mu\end{array}$ & $f_{\dot{\varepsilon}, T}$ & $\varepsilon$ & ${\dot{\operatorname{c}_{1}}}_{\min ^{-1}}$ & $\dot{\varepsilon}_{\min ^{-1}}$ & $\begin{array}{c}D_{1} \\
\mu\end{array}$ & $\begin{array}{l}D_{2} \\
\mu\end{array}$ & $g_{\varepsilon, T}$ & $m$ & $a$ \\
\hline - & $\overline{7}$ & - & $\overline{0}$ & $\overline{0}$ & - & - & - & - & - & - & - & - & - & - \\
\hline & $7.6 \times 10^{-3}$ & 0.04 & 0.70 & 9.7 & 19 & 1.02 & 0.70 & $7.6 \times 10^{-3}$ & $2.5 \times 10^{-2}$ & 19 & 14.6 & -0.22 & 0.28 & 3.59 \\
\hline $550^{\circ} \mathrm{C}$ & $2.5 \times 10^{-2}$ & 0.10 & 0.70 & $\begin{array}{l}9.1 \\
0.7\end{array}$ & $\begin{array}{l}14.6 \\
125\end{array}$ & 0.68 & 0.70 & $2.5 \times 10^{-2}$ & $7.9 \times 10^{-2}$ & 14.6 & 13.5 & -0.07 & 0.43 & 2.31 \\
\hline & $3.1 \times 10^{-1}$ & 0.30 & 0.70 & 9.7 & 12.1 & 0.05 & & $1.9 \times 10^{-2}$ & $3.1 \times 10^{-1}$ & 15.3 & 12.1 & -0.12 & 0.38 & 2.61 \\
\hline $\mathrm{Cu}-\mathrm{Al}$ & $3.6 \times 10^{-3}$ & 0.43 & 1.56 & 10 & 14.5 & 0.33 & 1 & $3.6 \times 10^{-3}$ & $3.6 \times 10^{-2}$ & 12 & 7.5 & -0.20 & 0.30 & 3.33 \\
\hline $520^{\circ} \mathrm{C}$ & $3.6 \times 10^{-2}$ & 0.40 & 1.42 & 10 & 11.5 & 0.14 & 1 & $3.6 \times 10^{-2}$ & $3.6 \times 10^{-1}$ & 7.5 & 7.5 & 0 & 0.5 & 2 \\
\hline & $3.6 \times 10^{-1}$ & 0.51 & 1.83 & 7 & 7.5 & 0.05 & & & & & & & & \\
\hline $60 / 40 \mathrm{~F}$ & $10^{-2}$ & 0.40 & 0.70 & 17.5 & 20 & 0.45 & 0.70 & $10^{-2}$ & $10^{-1}$ & 20 & 14 & -0.15 & 0.35 & 2.86 \\
\hline 600 & $10^{-1}$ & 0.40 & 0.70 & 13.5 & 14 & 0.12 & & & & & & & & \\
\hline $\mathrm{Sn}-1 \% \mathrm{Bi}$ & $10^{-2}$ & 0.15 & 1 & 2 & 4.5 & 0.95 & 1 & $10^{-2}$ & $10^{-1}$ & 4.5 & 2.3 & -0.29 & 0.21 & 4.76 \\
\hline $20^{\circ} \mathrm{C}$ & $10^{-1}$ & 0.10 & 1 & 2 & 2.3 & 0.16 & 1 & $10^{-1}$ & 1 & 2.3 & 2 & -0.06 & 0.44 & 2.27 \\
\hline Experimental & 1 & 0.10 & 1 & 2 & 2 & 0 & & & & & & & & \\
\hline & $10^{-5}$ & 0.10 & 1 & 7 & 22 & 1.27 & 1 & $10^{-5}$ & $10^{-4}$ & 22 & 8.2 & -0.43 & 0.07 & 14.3 \\
\hline $\mathrm{Sn}-1 \% \mathrm{Bi}$ & $10^{-4}$ & 0.10 & 1 & 3.1 & 8.2 & 1.08 & 1 & $10^{-4}$ & $10^{-3}$ & 8.2 & 5.1 & -0.21 & 0.29 & 3.45 \\
\hline $20^{\circ}$ & $10^{-3}$ & 0.10 & 1 & 2.3 & 5.1 & 0.88 & 1 & $10^{-3}$ & $10^{-2}$ & 5.1 & 4.7 & -0.04 & 0.46 & 2.17 \\
\hline Theoretical & $10^{-2}$ & 0.10 & 1 & 2.25 & 4.7 & 0.82 & 1 & $10^{-2}$ & $10^{-1}$ & 4.7 & 4.6 & -0.01 & 0.49 & 2.04 \\
\hline & $10^{-}$ & 0.10 & 1 & 25 & 6 & 9 & & $10^{-1}$ & 1 & 4.6 & 4.6 & 0 & 0.5 & \\
\hline
\end{tabular}

Results showing grain growth and its influence on the parameters of the constitutive equation for several superplastic alloys. Values are computed from published data [25, 26,32, 51]. 
constitutive equation which takes into account the structural variation, should obey one of the three previously given types. The scarcity of experimental results relating structural parameters as well as thermomechanical parameters leaves doubt as to which equation applies. Nevertheless we shall attempt to show how a single equation of type $\left(1^{\prime}\right)$, in which the initial grain size is replaced by a parameter characteristic of the structure at any time during the deformation, can satisfactorily describe regions I and II of the $\log \sigma-\log \dot{\varepsilon}$ curve. We shall assume that the structure is approximately equiaxed and can be represented by a single parameter $D$.

The type $\left(1^{\prime}\right)$ relationship can be written in the differential form :

$\delta \log \sigma=m^{\prime} \delta \log \dot{\varepsilon}+m^{\prime} \frac{Q^{\prime}}{k} \delta\left(\frac{1}{T}\right)+m^{\prime} a^{\prime} \delta \log D$

where $m^{\prime}, Q^{\prime}$ and $a^{\prime}$ are metallurgical coefficients related to the strain rate, temperature and grain size respectively when the latter is taken into consideration.

We can also write :

$$
\begin{array}{r}
\delta \log D=\left(\frac{\delta \log D}{\delta \varepsilon}\right)_{\dot{\varepsilon}, T} \delta \varepsilon+\left(\frac{\delta \log D}{\delta \log \dot{\varepsilon}}\right)_{\varepsilon, T} \delta \log \dot{\varepsilon}+ \\
+\left(\frac{\delta \log D}{\delta\left(\frac{1}{T}\right)}\right)_{\varepsilon, \dot{\varepsilon}} \delta\left(\frac{1}{T}\right)+\delta \log D_{\mathrm{i}}
\end{array}
$$

or

$$
\begin{aligned}
\delta \log D=f_{\dot{\varepsilon}, T} \delta \varepsilon+g_{\varepsilon, T} \delta & \log \dot{\varepsilon}+ \\
& +\frac{h_{\varepsilon \dot{\varepsilon}}}{k} \delta\left(\frac{1}{T}\right)+\delta \log D_{\mathrm{i}}
\end{aligned}
$$

where $\delta \log D_{\mathrm{i}}$ represents the variation of the initial grain size.

Equation (4) can now be written :

$$
\begin{aligned}
\delta \log \sigma=m^{\prime} & a^{\prime} f_{\dot{\varepsilon}, T} \delta \varepsilon+m^{\prime}\left(1+a^{\prime} g_{\varepsilon, T}\right) \delta \log \dot{\varepsilon}+ \\
& +\frac{m^{\prime}}{k}\left(Q^{\prime}+a^{\prime} h_{\varepsilon, \dot{\varepsilon}}\right) \delta\left(\frac{1}{T}\right)+m^{\prime} a^{\prime} \delta \log D_{\mathrm{i}}
\end{aligned}
$$

If the grain size evolution is not considered, type (1) relation applies and can be written, in a differential form

$$
\delta \log \sigma=m \delta \log \dot{\varepsilon}+\frac{m Q}{k} \delta\left(\frac{1}{T}\right)+m a \delta \log D_{\mathrm{i}}
$$

where $m, Q$ and $a$ are the rheological parameters obtained on the initial structure.

The comparison between equations (7) and (8) points out the influence of the structural evolution on the constitutive equation. This influence appears as :
- Apparent strain hardening given by $m^{\prime} a^{\prime} f_{\dot{\varepsilon}, T}$. It is negligible at high strain rates but becomes very large at lower rates. For instance, taking 0.5 and 2 as reasonable values for $m^{\prime}$ and $a^{\prime}$ respectively, and a value of 0.5 for $f \cdot$, at a strain of 1 and at a strain rate of $10^{-2} \mathrm{~min} .^{-1}$, the amount of strain hardening computed is of the same order as that observed during cold deformation of metals. This apparent strain hardening is always observed when grain growth is significant $[25,26,32,50]$ (Fig. 6).

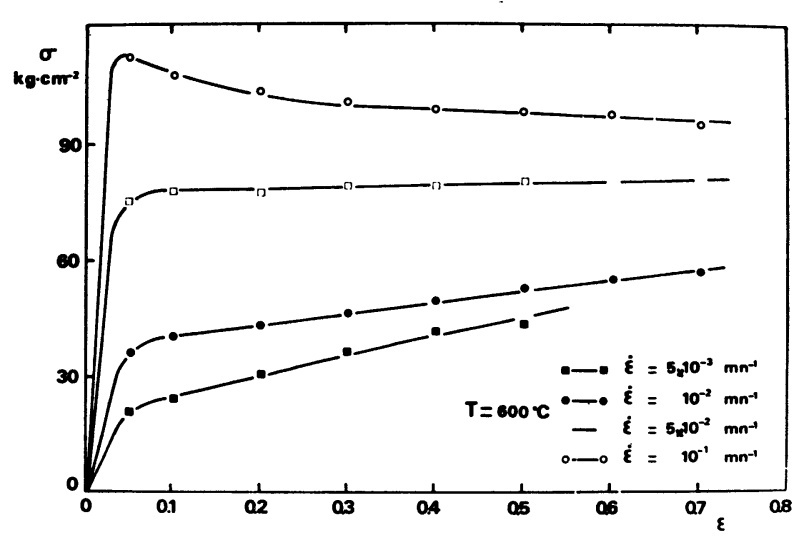

FIG. 6. - True stress against true strain at constant strain rates for $60 / 40$ brass deformed at $600{ }^{\circ} \mathrm{C}$. This shows the strain hardening due to grain growth and the softening due to the evolution to the equiaxed structure at the higher strain rates.

- An apparent strain rate sensitivity of the stress $m=m^{\prime}\left(1+a^{\prime} g_{\varepsilon, T}\right)$. As $g_{\varepsilon, T}$ is negative, the $m$ value, which does not take into account grain growth, is always lower than $m^{\prime}$ and tends towards $m^{\prime}$ when the strain rate in the superplastic region increases (see table II). The theoretical variation of $m$ with strain rate is plotted in figure 7 , using values of $g_{\varepsilon, T}$ computed from the Clark and Alden model [51]. It can be readily seen that $m$ decreases when the strain rate decreases.

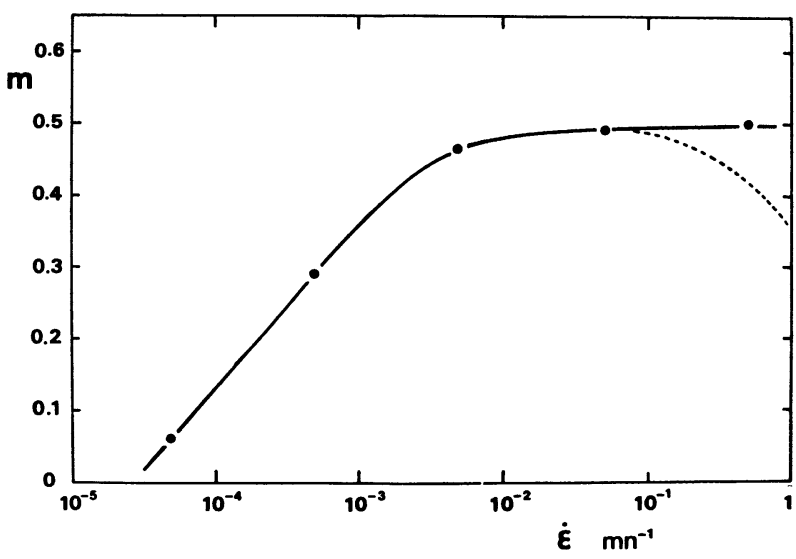

FIG. 7. - Theoretical variation of the rheological coefficient $m$ with strain rate for the $\mathrm{Sn}-1 \% \mathrm{Bi}$ alloy. The values are computed from $m=m^{\prime}\left(1+a^{\prime} g_{\varepsilon, T}\right)$ where $m^{\prime}=0.5, a^{\prime}=2, g_{\varepsilon, T}$ being obtained from theoretical analysis [51]. The high strain rate region for which the values of the rheological coefficient $m$ are decreasing (shown as dotted line) is not taken into account in the calculation. 
- An activation energy $Q$ given by :

$$
m Q=m^{\prime}\left(Q^{\prime}+a^{\prime} h_{\varepsilon, \dot{\varepsilon}}\right)
$$

or

$$
Q=\frac{Q^{\prime}+a^{\prime} h_{\varepsilon, \dot{\varepsilon}}}{1+a^{\prime} g_{\varepsilon, T}}
$$

For larger strain rates in the superplastic region, $g_{\varepsilon, T}$ is equal to zero and the $Q$ value is lower than $Q^{\prime}$. The $Q$ variation is, however difficult to estimate owing to the unknown quantity $h_{\varepsilon, \dot{\varepsilon}}$, but the trend towards larger values at low strain rates may be thus justified.

- The influence of the initial grain size through the parameter

$$
a=\frac{a^{\prime}}{1+a^{\prime} g_{\varepsilon, T}}
$$

greater or equal to $a^{\prime}$. Table II gives values of $a^{\prime}$ for a number of alloys.

These results show that grain growth, which takes place concurrently with deformation, modifies the parameters of the constitutive equation, this influence being more marked at low strain rates. The type $\left(1^{\prime}\right)$ relationship, which takes into account the grain size variations, describes regions II and I. The existence of region $I$ has indeed often been shown by :

- A sigmoidal variation of the $\log \sigma-\log \dot{\varepsilon}$ curve. Now, as was seen earlier, this variation can be determined either by strain rate jumps using a single sample or from several samples deformed at different strain rates. In both cases, the stress increase due to grain growth shifts the stress values upwards at the lower strain rates, thus giving the curve its characteristic sigmoidal appearance. This result has been demonstrated for the fine-grained eutectic $\mathrm{Al}-\mathrm{Cu}$ alloy for which growth occurs at low strain rates [50]. On the other hand, for somewhat larger and therefore more stable grain sizes, the slope of the $\log \sigma-\log \dot{\varepsilon}$ curve remains constant over a large strain rate range (Fig. 8). In a similar manner, the variation of the strain rate sensitivity coefficient with strain rate, as determined by

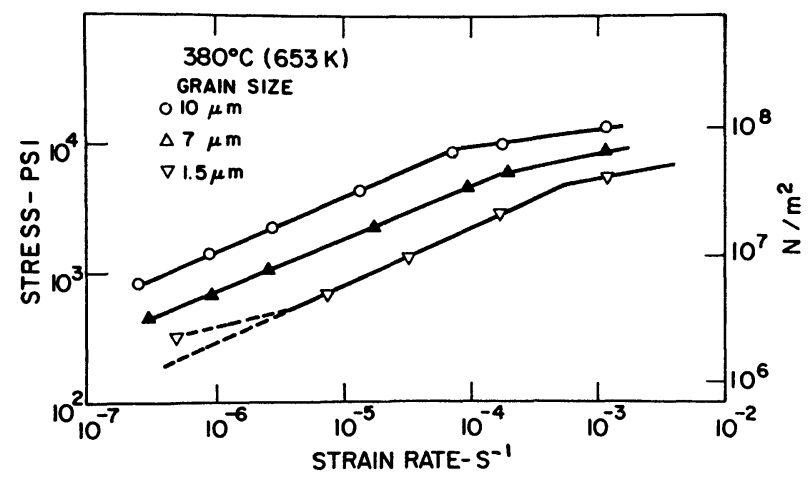

FIG. 8. - Log stress - Log strain rate plot as a function of the initial grain size at $380^{\circ} \mathrm{C}$ for an $\mathrm{AlCu}$ eutectic alloy; points based on 15pct strain. Note the effect of grain growth of the $1.5 \mu \mathrm{m}$ material. After [50]. the strain rate jump method, is affected by grain growth [55]. Different methods have been proposed [39, $40,56,57]$. However, it has been shown that $m$ values remain constant and close to 0.5 over a large strain rate range if similar structural conditions are compared [58]. Similar conclusions may be drawn from stress relaxation techniques $[59,60]$ which, as a result of the very small strains involved, allow the determination of the strain rate sensitivity coefficient for a constant structure. This is possible because it has been shown that, during strain interruptions, the grain size continues to increase but at a far lower rate than it does during deformation [51].

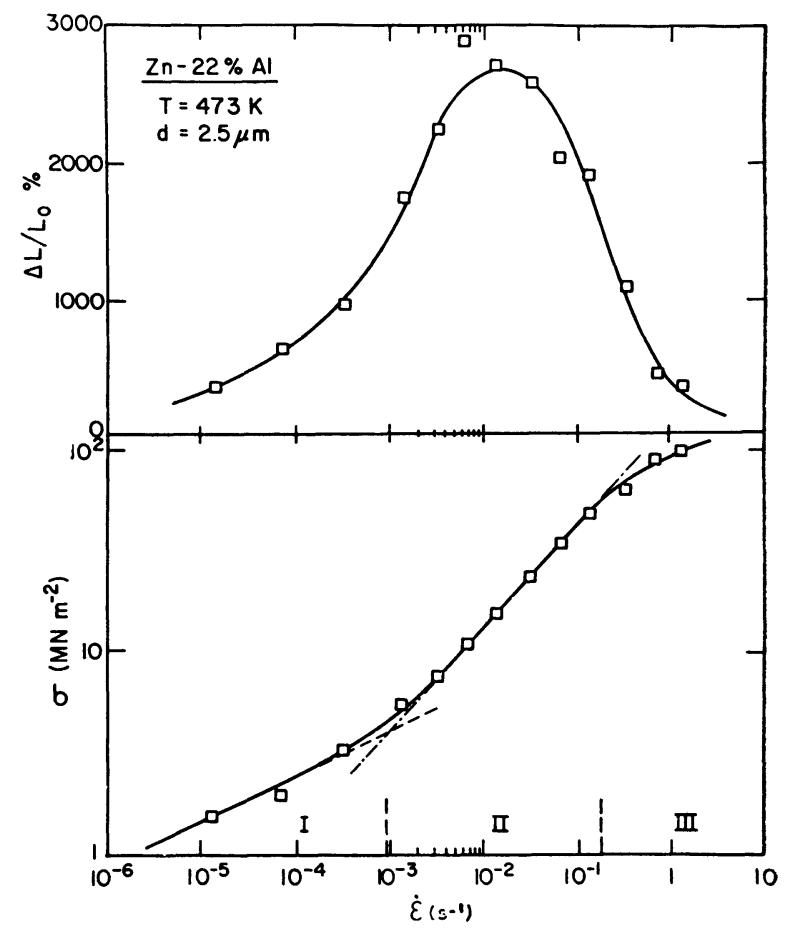

FIG. 9. - Upper : Elongation at fracture versus initial strain rate for a $\mathrm{ZnAl}$ eutectoid alloy of $2.5 \mu \mathrm{m}$ initial grain size tested in tension at $200^{\circ} \mathrm{C}$.

Lower : the corresponding plot of maximum flow stress versus strain rate. After [62].

- Smaller elongations than those of region II [61, 62] (Fig. 9). These can be rationalized by the lower values of the rheological coefficient $m-$ but not $m^{\prime}-$ in region I (equation (7)). Indeed, experiments [63-66] and plastic stability studies [67-70] have shown that the higher the $m$ coefficient, the larger the strain at which necking occurs. Furthermore, plane strain analysis of the deformation also demonstrates the strong influence of the $m$ coefficient [71-75].

- An activation energy different from that measured in region II. Now, the previous analysis shows how a lower and strain rate dependent $Q$ value can be derived from a constant activation energy $Q^{\prime}$. Such variations have been observed particularly in the case of the eutectoid $\mathrm{Zn}-\mathrm{Al}$ alloy [76]. 
- A different initial grain size dependence on the strain rate. For instance, values of the coefficient a of 2.5 and greater have been measured on a $\mathrm{Zn}-\mathrm{Al}$ alloy deformed at low strain rates [1]. These values are in very good agreement with those derived from the earlier analysis (see table II).

- A relative increase $\Delta D / D_{\mathrm{A}}$ of the grain size due to deformation lower than in region II $(\Delta D$ represents the difference between the grain size $D_{\mathrm{D}}$ after deformation and that $D_{\mathrm{A}}$ of a sample annealed at the same temperature and for the same time [51]). This smaller increase was attributed to a difference in the amount of grain boundary sliding. It is however worthy to note that measurements were carried out at low strains - less than $30 \%$ - for which the material is likely to be still in the transient region.

Grain growth offers thus an interpretation for the main characteristics of region I, i. e. low $m$-values, lower elongations, different activation energies and a different influence of the initial grain size. These facts may be added to the earlier description of the deformation in the transient region. It becomes necessary therefore, in order to study the constitutive equation to free ourselves from the transient region on the one hand and on the other hand, to take into account the grain size variation during deformation. Such an investigation has been carried out on $\mathrm{Cu}-\mathrm{P}$ alloys of various compositions obtained by extrusion or splat-cooling followed by an anneal [29]. It was shown that a unique relationship does exist between the thermomechanical variables $\sigma, \dot{\varepsilon}, T$ and the structure parameters over a large strain rate range, when the structural evolution is taken into account. In particular, the strain rate sensitivity of the stress $m^{\prime}$ was observed to be constant and equal to 0.5 (Fig. 10). The activation energy $Q^{\prime}$ was found to be close to the volume self-diffusion activation

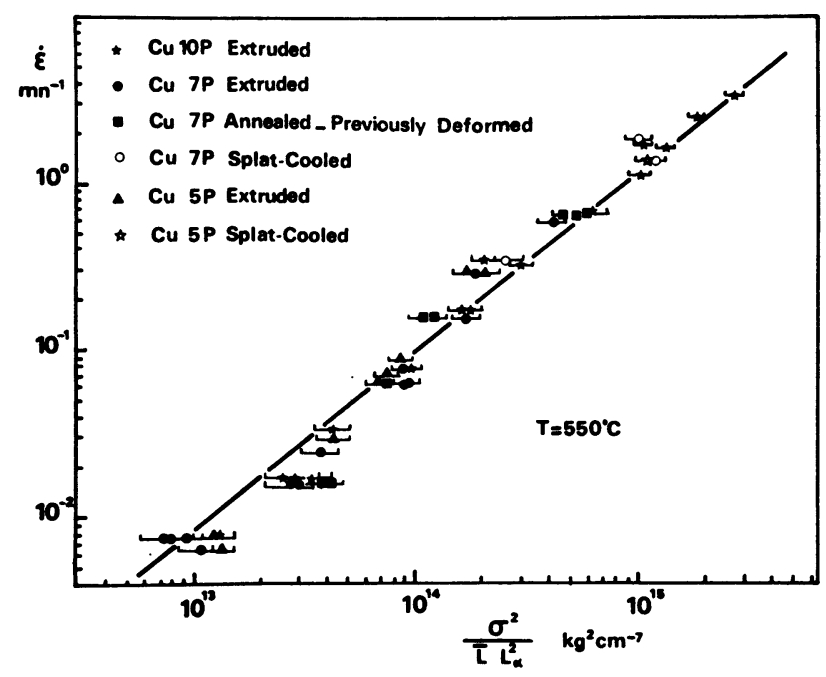

Fig. 10. - Relation between mechanical and structural parameters $\bar{L}, L_{\alpha}$ deduced from metallographic observations for the superplastic deformation of CuP alloys of different compositions and following different thermomechanical treatment. The slope of the curve is equal to unity. energy $Q_{v}$ for copper. However, it is possible that this energy is close to the phase boundary self diffusion energy [77]. On the other hand, the value of $Q$ varies with strain rate but remains close to $1 / 2 Q_{v}$. Finally, the value of $a^{\prime}$ was found equal to 3 if a single grain size was assumed for the material. Unfortunately, studies of this kind have not been carried out to date on other two-phase alloys and so the relations obtained on $\mathrm{Cu}-\mathrm{P}$ alloys cannot be generalized.

The study of the structural evolution during the transient and pseudo-steady-state region as well as its influence on the constitutive equation calls for several remarks :

- The transition towards the equiaxed structure and the grain growth have been considered as separate and successive processes. In fact, these evolutions occur simultaneously and therefore the theoretical analysis in each case cannot readily be tested against experimental results. As discussed earlier, the transition towards the equiaxed state leads to strain softening and increases $m$ values, whereas grain growth tends to increase the stress and decrease $m$. In certain cases, these two mechanisms can balance each other and give the appearance of a steady state [25].

- The grain growth analysis is supported by some experimental results obtained on superplastic materials having particularly stable structures : no apparent strain hardening $[78,79]$, no region I [79, 80], constant $m$ value equal to 0.5 over a large strain rate range $[50,80]$, large elongations even at the lowest strain rates [50].

- Grain growth has been considered so far as the only phenomenon taking place during pseudo-steadystate flow. However, on many superplastic alloys, an uniformly distributed damage appears $[30,33,39,66$, 81-83]. Plastic stability studies have shown that microvoid generation during deformation increases the instability by decreasing the strain rate sensitivity of the stress [70]. This phenomenon acts then in a similar way to grain growth and complicates further the comparison between the theoretical predictions and the experimental results.

4. Discussion of the proposed models. - All the models put forward to interpret the overall strain rate dependence of the stress assume a single-phase material, whose structure can be characterized by a parameter associated with the initial condition prior to deformation. As discussed earlier, this structure evolves and the $\log \sigma-\log \dot{\varepsilon}$ curves are generally obtained for different structures. Under these circumstances, it appears that there is little point in attempting to fit experimental results with an equation making use of an initial grain size $D_{\mathrm{i}}$ or a constant size $D$. These various models, involving grain boundary sliding with accommodation either by dislocation mechanisms $[12,34,60$, $84,84]$ or by diffusion $[41,86]$ appear, however, flexible enough to allow an interpretation of the constitutive 
equation while taking into account the structural evolution. Indeed, it is clear that the adjustment or the modification of the parameters called for by these models always succeed in fitting any particular set of experimental results. We do not imply that these advanced models have no sound basis or physical ground [87], but we would like to stress the following points :

- The agreement between a model and an experimental constitutive equation does not establish in any way that the processes involved are really taking place [87].

- Microstructural observations are too scarce and often contradictory : there is too little reliable data to test the validity of any particular model.

- The constitutive equation derived for the $\mathrm{Cu}-\mathrm{P}$ alloy, which takes into account the structural evolution during deformation [29], lacks support to allow its generalization to other alloys.

- Superplastic materials are two-phase alloys and it appears necessary to consider the role of each phase during deformation.

Such models for two-phase alloys do not exist, except for a very recent approach [77]. Our purpose in this last section is not to propose a model, but simply to develop an hydrodynamic analogy to describe the experimental relationships as well as the main characteristics of superplastic materials.

5. Hydrodynamic analogy. - The type of structure observed in superplastic material suggests that phases A and $B$ play a different role and behave differently during deformation. The B-phase appears to have a two-fold action : firstly to decrease the mean free path in the A-phase and secondly, to keep it small by restricting grain growth. This last point is supported by experimental results for microduplex structures which show that the least amount of grain growth occurs when the phases exist in roughly equal volume fractions [53]. Furthermore, scanning electron microscope observations in particular, have shown a difference in behaviour between the two phases [88] : the B-phase grains rotate but undergo practically no deformation, whereas the A-phase plastically deforms while accommodating the rotations of the B-phase. Under these conditions, the deformation behaviour of superplastic materials could be viewed as that of a fluid in which a given concentration of a hard phase is present [89]. We have been successful in simulating this deformation on a rate sensitive non-metallic material, in which non deformable particles were present. Thus, we were able to show that the form of the overall constitutive equation was not modified by the presence of hard particles, and that $m$ did not change appreciably. The experimental conditions and the most significant results of this study are given in the appendix. Several conditions, however, must be met to confirm the validity of this hydrodynamic analogy:
5.1. - In the material used for the simulations, the constitutive equation is not modified by the presence of non-deformable particles. This condition must also be fulfilled for the superplastic material, for which the constitutive equation has a high $m$ value. Is this the case for the partial equation of the hypothetical material A having a small mean free path limited by grain and phase boundaries ? Two types of approach can be considered, theoretical and experimental :

5.1.1. Theoretical. - When the mean free path is small, the deformation takes place without formation of dislocation cells. Indeed, for a stress level close to that applied in the superplastic region, the size of the cells which could form would be larger than this mean free path [90]. This hypothesis is supported by transmission electron microscope observations which have shown that, following deformation at stress levels characteristic of the superplastic behaviour, the grains are cell-free and contain few dislocations [26, 39, 84, 91-95]. At higher stresses, the cell size becomes smaller than the mean free path; the deformation is then analogous to that of conventional materials. The occurrence of subgrains explains the transition between regions II and III [96].

Two types of mechanisms can be considered when the deformation occurs without cell formation for materials having a small mean free path :

- A vacancy diffusion mechanism of the NabarroHerring [2, 3] or Coble [4] type, which leads to a linear stress dependence. Ashby and Verrall [86] developed a more detailed analysis of these mechanisms by comparing the deformation of a fine-grained material with the flow of an oil emulsion. The relation derived thus combines the Nabarro-Herring and Coble creep equations. It predicts a larger strain rate as a result of shorter diffusion paths on one hand and less mass transfer on the other.

- A slip mechanism controlled by dislocation climb in the boundaries. It has been shown in this case that at low stresses the $m$ coefficient is 0.5 [97]. However, given the assumptions underlying the microscopic mechanism likely to be operating, it is not impossible to obtain different values [98].

Furthermore, the distinction between the role of grain boundaries and phase boundaries has to be made regarding their vacancy and dislocation emitting or absorbing capacities. There is indeed some evidence that the maximum value of $m$ is larger (close to 0.8 ) in preponderantly single-phase materials with an (a)-type structure than in materials with a (b)-type structure for which $m$ is about 0.5 (Figs. 13 and 14, p. 243, ref. [22]).

5.2.1. Experimental. - The study of the constitutive equation of a pure metal with very small grains at high temperature is impossible. This type of structure is obviously unstable as a very large grain growth will readily occur. A constitutive equation with $m=0.5$ 
has been reported on very fine grained zinc [99]. However in this case, it is likely that the structure was stabilized by microprecipitates at grain boundaries, which in turn could have had a significant influence on the constitutive equation of the pure material [100].

5.2. - In the material used for simulation purposes, the B-phase is constituted of non-deformable particles, although this is not really the case for superplastic materials. In many alloys, however, the phases have very different ductilities, so that it is possible to consider that this condition is nearly achieved. The analogy will therefore be limited to these alloys.

5.3. - The constitutive equation of the interface is very poorly known for superplastic materials. The studies dealing with grain boundaries have been mostly concerned with the influence of crystallographic orientation in bicrystals $[101,102]$ and the contribution of grain boundary sliding to the overall deformation in polycrystals $[103,104]$. The sliding rate has been theoretically related to the shear stress in the boundary plane, taking into consideration the dislocation network at the interface $[105,106]$. A linear stress dependence has been predicted. Agreement has been reported from work on zinc bicrystals deformed at very low stresses [107]. Such relations can however only be determined during the early stages of deformation [108] Pioneer studies on phase boundaries have been carried out on the $\mathrm{Pb}-\mathrm{Sn}$ lamellar eutectic alloy [108-110] and on two-phase $\mathrm{CuAl} \alpha-\mathrm{CuAl} \beta$ bicrystals [111]. Large amounts of sliding at the interface were observed to take place under very low shear stresses. The sliding rate is very sensitive to the shear stress but the exact value of the strain rate sensitivity cannot be determined for the moment. Furthermore, the constitutive equation at the matrix-particle interface is totally unknown for the simulation material. It is likely, however, that this is of a Newtonian-type given the nature of the various components.

The conditions required to confirm the validity of this hydrodynamic analogy do not appear perfectly fulfilled. In spite of these difficulties and particularly in the interface behaviour, this analogy can be considered as a valid one, especially as it describes in a satisfactory manner the main characteristics of superplastic materials :

- The texture evolves in a different way for the two phases ; the B-phase texture quickly tends to become random, whereas that of the A-phase evolves more slowly and retains certain components $[112,113]$. The process by which the B-phase evolution takes place is a rotation of the B-particles, which results from the twisting moment of the forces arising during plastic flow. Such rotations have often been observed $[19,88$, 114-116].

- Sliding occurs mostly at phase boundaries, the grain boundaries playing little role during superplastic deformation :
- Phase boundaries become rounder after deformation $[24,117,118]$.

- When microvoids are formed as a result of sliding, they are distributed preferentially along the interfaces [30, 33, 39, 82, 119-121]. According to this model, sliding results from the relative movement of the matrix and the particles and therefore does not constitute a specific deformation mechanism. However, when the sliding is difficult or impossible, voids form along the interfaces, leading to early fracture. This microvoid formation process has been often observed for copper alloys and steels for which relatively small elongations have been obtained in spite of high $m$ values. It appears therefore that a short mean free path in the ductile phase and a discontinuous non-deformable phase are necessary conditions to obtain an overall constitutive equation with high $m$ values. These conditions are not, however, sufficient to guarantee large elongations before fracture ; it is also necessary that sliding at the interfaces occurs without cavity formation. This is the case for WC-Co alloys which have a short mean free path in the Co-phase and high $m$ values at low stresses [122] and nevertheless display very low elongations.

- Superplastic behaviour may be observed even in the case of an elongated B-phase (see section 3.1). Two hypotheses may then be proposed to explain the higher stresses obtained when compared to those of the equiaxed condition. The first one involves the shape of the particles (and needs to be verified by the hydrodynamic analogy) whereas the second one is based on the more heterogeneous distribution of the mean free paths within the A-phase. In the latter approach, the operating deformation mechanisms may involve subgrains; the stress is then higher and the $m$ values are lower (Fig. 5).

6. Conclusion. - The influence of the structure on the constitutive equations of superplastic materials has been studied and can be summarized as follows:

- During deformation, the structure of the material undergoes a transition towards the equiaxed condition as well as grain growth. These two phenomena may modify the parameters of the constitutive equations and provide an interpretation for region $\mathrm{I}$, which is often observed at low strain rates.

- Constitutive equations, in which the initial size of the grains or phases is taken as the structure parameter, are valid only within a rheological approach, particularly in view of mechanical studies of plastic stability. The agreement between the models and the equations thus derived does not prove the validity of the former.

- Superplastic materials are two-phased and their structures are characterized by stable and short mean free paths in the most ductile phase. Deformation could then be viewed as analogous to that of a fluid containing non-deformable particles. This hydrodynamic analogy could describe the phase boundary sliding, the 
rotation of the hardest phase and the different textural evolution of each phase.

- A short mean free path in the ductile phase guarantees high $m$ values in the constitutive equation, as long as the hard phase is discontinuous, but does not ensure large elongations to fracture. The latter property requires the further condition that sliding at the interfaces does not lead to extensive and fast growing cavitation in the material.

Acknowledgments. - The authors wish to acknowledge their grateful thanks to the Délégation Générale à la Recherche Scientifique et Technique for financially supporting the superplasticity research. They also wish to thank Dr. J. Zarka for his assistance with the hydrodynamic analogy.

Appendix. - The material used for the simulation of superplastic behaviour was a mixture of $80 \%$ vaseline with $20 \%$ paraffin in which glass spheres of diameters ranging between 0.2 and $0.6 \mathrm{~mm}$ were dispersed. The volume fraction of the glass spheres was equal to that of the vaseline-paraffin mixture. The direct extrusion process was chosen for the determination of $\mathrm{m}$, the strain rate sensitivity of the stress, due to its ease of operation for extremely soft materials which cannot be tested in tension or compression. Furthermore, a recent study [123] of the extrusion of rate sensitive materials has shown that an analytical expression of the extrusion force could be derived as a function of the experimental and material variables, assuming that the constitutive equation obeys a relationship of the type :

$$
\sigma=\sigma_{0}\left(\frac{\dot{\varepsilon}}{\dot{\varepsilon}_{0}}\right)^{m} .
$$

This analytical expression can be written as :

$$
\begin{aligned}
P=\frac{2 \sigma_{0}\left(4 D_{0}^{2} V_{0} \operatorname{tg} \alpha\right)^{m}(1+\mu \operatorname{cotg} \alpha)}{3 m+2 \mu \operatorname{cotg} \alpha} \times \\
\quad \times D_{\mathrm{f}}^{2 \mu \operatorname{cotg} \alpha}\left[D_{0}^{-(3 m+2 \mu \operatorname{cotg} \alpha)}-D_{\mathrm{f}}^{-(3 m+2 \mu \operatorname{cotg} \alpha)}\right]
\end{aligned}
$$

where $D_{0}$ is the initial diameter of the billet, $D_{\mathrm{f}}$ its final diameter, $2 \alpha$ the die angle, $\mu$ the coefficient of friction and $V_{0}$ the imposed ram velocity.
Assuming nearly friction-free conditions for the present material, equation (A2) takes the simpler form :

$$
P=\frac{2 \sigma_{0}\left(4 D_{0}^{2} V_{0} \operatorname{tg} \alpha\right)^{m}}{3 m}\left[D_{0}^{-3 m}-D_{\mathrm{f}}^{-3 m}\right] \text {. }
$$

This relation does not easily permit the determination of $m$ if the latter is not constant over the stress range. If $m$ is constant however, it can be obtained from the slope of the curve of the extrusion force versus the velocity on a Log-Log plot. Such a graph is given in figure A. Values of $D_{0}, D_{\mathrm{f}}$ and $\alpha$ are $35 \mathrm{~mm}, 6.5 \mathrm{~mm}$ and $30^{\circ}$ respectively. It may be seen that :

- the material is strain rate sensitive, with a constant value of $m$ of 0.22 ,

- the presence of the glass spheres, in a volume fraction equal to that of the matrix, does not affect the $m$ coefficient. The extrusion force however, is about doubled.

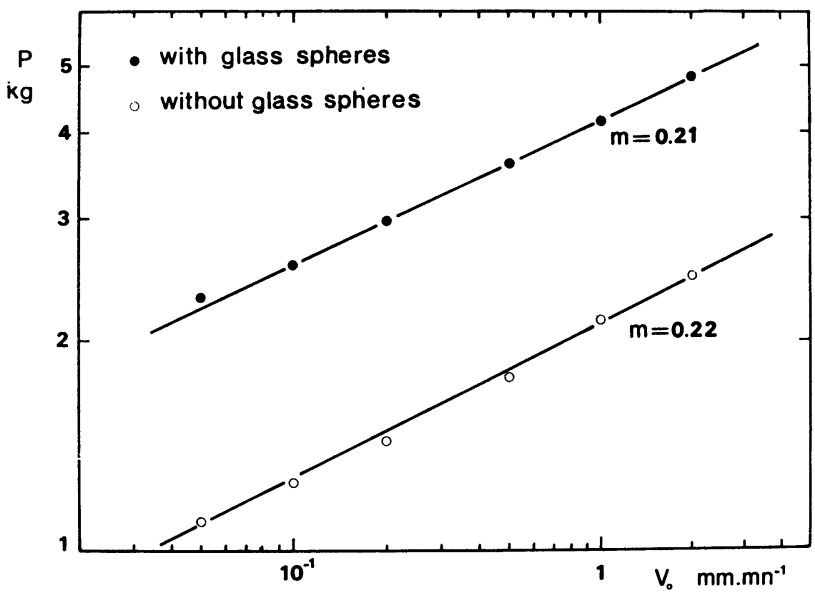

FIG. A. - Ram velocity dependence of the extrusion force for the simulation material without spheres or with a $50 \%$ volume fraction of glass spheres. The slope of curves gives the rheological coefficient $m$.

The rheological coefficient $m$ appears therefore nearly insensitive to the presence of hard second phase particles. Further studies are under way to determine the influence of the size, shape and volume fraction of the second phase on the overall equation of the material, i. e. the $\sigma_{0}, \dot{\varepsilon}_{0}$ and $m$ values of the relation (A1).

\section{References}

[1] Vaidya, M. L., Murty, K. L. and Dorn, J. E., Acta Met. 21 (1973) 1615.

[2] Nabarro, F. R. N., Report on Conference on Strength of Solids, Physical Society London, p. 75 (1948).

[3] Herring, C., J. Appl. Phys. 21 (1950) 437.

[4] Coble, R. L., J. Appl. Phys. 34 (1963) 1679.

[5] Hilliard, J. E., Met. Prog. 85 (1964) 99.

[6] Alden, T. H., J. Aust. Inst. Met. 14 (1969) 207.
[7] Edington, J. W., Melton, K. N. and Cutler, C. P., Prog. Mater. Sci. 21 (1976) 61.

[8] Mohamed, F. A., Shei, S. and Langdon, T. G., Acta Met. 23 (1975) 1443.

[9] Cahoon, J. R., Met. Sci. 9 (1975) 346.

[10] Mohamed, F. A. and Langdon, T. G., Acta Met. 23 (1975) 117.

[11] Gifkins, R. C., Scripta Met. 10 (1976) 433. 
[12] Gifkins, R. C., Met. Trans. 7A (1976) 1225.

[13] LI, J. C. M., Dislocation Dynamics Ed. A. R. Rosenfield et al. New York (McGraw Hill) 1969, p. 87.

[14] Holt, D. L. and Backofen, W. A., Trans. Amer. Soc. Met. 59 (1966) 755.

[15] Backofen, W. A., Azzarto, F. J., Murty, G. S. and ZeHR, S. W., Ductility, London (Chapman and Hall) 1967, p. 279.

[16] KARIM, A., Scripta Met. 3 (1969) 887.

[17] Backofen, W. A., MurTy, G. S. and Zehr, S. W., Trans. A. I. M. E. 242 (1968) 329.

[18] Burton, B., Scripta Met. 5 (1971) 669.

[19] Geckinli, A. E. and Barrett, C. R., J. Mat. Sci. 11 (1976) 510.

[20] Alden, T. H., Acta Met. 15 (1967) 469.

[21] HART, E. W., Acta Met. 15 (1967 b) 1545.

[22] AldEN, T. H., Treatise on Materials Science and Technology, vol. 6, Plastic Deformation of Materials, Ed. Arsenault, R. J. (Academic Press), 1975, p. 225.

[23] Suery, M. and BAudelet, B., J. Mat. Sci. 10 (1975) 1022.

[24] Stowel, M. J., Robertson, J. L. and Watts, B. M., Met. Sci. J. 3 (1969) 41.

[25] Suery, M. and Baudelet, B., J. Mat. Sci. 8 (1973) 363.

[26] Watts, B. M. and Stowell, M. J., J. Mat. Sci. 6 (1971) 228.

[27] Turner, D. M., M. A. Sci. Thesis, University of British Columbia (1971).

[28] Donaldson, K. C., Ph. D. Thesis, U. B. C. (1971).

[29] Herriot, G., Baudelet, B. and Jonas, J. J., Acta Met. 24 (1976) 687.

[30] Smith, C. I., Norgate, B. and Ridley, N., Met. Sci. 5 (1976) 182.

[31] Suery, M., Baudelet, B., Labulle, B. and Petipas, C. Scripta Met. 8 (1974) 703.

[32] Herriot, G., Suery, M. and Baudelet, B., Scripta Met. 6 (1972) 657.

[33] Sagat, S. and Taplin, D. M. R., Acta Met. 24 (1976) 307.

[34] Hayden, H. W., Floreen, S. and Goddell, P. D., Met. Trans. 3 (1972) 833.

[35] Holt, D. L. and Backofen, W. A., A. S. M. Trans. Quart. 59 (1966) 755.

[36] Hori, S., Furushiro, N. and Kawaguchi, S., Proceedings of the Nineteenth Japan Congress on Materials Research, Kyoto (1976).

[37] Homer, C., Lechten, J. P. and Baudelet, B., Met. Trans. 8A (1977) 1191

[38] Lechten, J. P., Homer, C., private communication.

[39] Morrison, W. B., Trans. Quart. A. S. M. 6 (1968) 423.

[40] Backofen, W. A., Turner, I. R. and Avery, D. H., Trans. A. S. M. Quart. 57 (1964) 980.

[41] ZeHR, S. W. and BACKOFEN, W. A., Trans. Quart. A. S. M. 61 (1968) 300.

[42] Lee, D. and Backofen, W. A., Trans. AIME 239 (1967) 1034.

[43] Alden, T. H. and Schadler, H. W., Trans. AIME 242 (1968) 825.

[44] NaZiri, H. and Pearce, R., J. Inst. Metals 101 (1973) 197.

[45] Dunlop, G. L. and Taplin, D. M. R., J. Mat. Sci. 7 (1972) 316.

[46] Chaudhari, P., Acta Met. 15 (1967) 1777.

[47] Kossowski, R. and Bechtold, J. H., Trans. AIME 242 (1968) 716.

[48] Cutler, C. P. and Edington, J. W., Met. Sci. J. 5 (1971) 201.

[49] DucheYne, P. and De Meester, P., J. Mat. Sci. 9 (1974) 109.

[50] RaI, G. and Grant, N. J., Met. Trans. 6A (1975) 385.

[51] Clark, M. A. and Alden, T. H., Acta Met. 21 (1973) 1195.

[52] Müller, P. and RassmanN, G., Z. Metal. 66 (1975) 213.

[53] Taplin, D. M. R. and Chandra, T., J. Mat. Sci. Lett. 10 (1975) 1642 .
[54] Bird, J. E., Mukherjee, A. K. and Dorn, J. E., Int. Conf. on quantitative relation between properties and microstructure, Haifa Israel, July 27-Aug 1 (1969).

[55] Nuttall, K., Inst. J. Mech. Sc. 13 (1971) 83.

[56] NaZIRI, H. and PearCe, R., J. Inst. Metals 97 (1969) 326.

[57] GiBBs, G. B., Phil. Mag. 13 (1966), 317.

[58] Hedworth, J. and Stowell, M. J., J. Mat. Sci. 6 (1971) 1061.

[59] Hart, E. W., Acta Met. 15 (1967) 351.

[60] Hayden, H. W. and Brophy, J. H., Trans. A. S. M. 61 (1968) 542.

[61] Dunlop, G. L. and Taplin, D. M. R., J. Mat. Sci. 7 (1972) 84.

[62] Ishikawa, H., Mohamed, F. A. and Langdon, T. G., Phil. Mag. 32 (1975) 1269.

[63] Morrison, W. B., Trans. AIME 242 (1968) 2221.

[64] WoOdFord, D. A., Trans. A. S. M. 62 (1969) 291.

[65] Avery, D. H. and BACKofen, W. A., A. S. M. Trans. Quart. 58 (1965) 551.

[66] Matuki, K. and Yamada, M., J. Japan Inst. Metals 37 (1973) 448.

[67] HART, E. W., Acta Met. 15 (1967a) 351.

[68] Campbell, J. D., J. Mech. Phys. Solids 15 (1967) 359.

[69] Jonas, J. J., Holt, R. A. and Coleman, C. E., Acta Met. 24 (1976) 911.

[70] Jonas, J. J. and Baudelet, B., Acta Met. 25 (1977) 43.

[71] Jovane, F., Int. J. Mech. Sc. 10 (1968) 403.

[72] Holt, D. L., Int. J. Mech. Sc. 12 (1970) 491.

[73] Cornfield, G. C. and Johnson, R. H., Int. J. Mech. Sc. 12 (1970) 479.

[74] Lechten, J. P., Patrat, J. C. and Baudelet, B., Revue Phys. Appl. 12 (1977) 7.

[75] Marciniak, Z., Kuczynski, K. and Pokora, T., Int. J. Mech. Sc. 15 (1973) 789.

[76] Naziri, H., Pearce, R., Henderson Brown, M. and Hale, K. F., Acta Met. 23 (1975) 489.

[77] Gitrus, J. H., Private Communication.

[78] Surges, K., M. Sci. Thesis University of British Columbia (1969).

[79] Baudelet, B. and Suery, M., J. Mat. Sci. 7 (1972) 512.

[80] Hayden, H. W., Gibson, R. C., Merrick, H. F. and BROPHY, J. H., Trans. Quart. 60 (1967) 3.

[81] Sagat, S., Blenkinsop, P. and Taplin, D. M. R., J. Inst. Metals 100 (1972) 268

[82] Dunlop, G. L., Shapiro, E., Taplin, D. M. R. and Crane, J., Met. Trans. 4 (1973) 2039.

[83] Karim, A., Holt, D. L. and BaCKofen, W. A., Trans. AIME 245 (1969) 1131.

[84] Ball, A. and Hutchison, M. M., Met. Sci. J. 3 (1969) 1.

[85] MukherJee, A. K., Mater. Sci. Eng. 8 (1971) 83.

[86] Ashby, M. F. and Verrall, R. A., Acta Met. 21 (1973) 149.

[87] PoIRIer, J. P., Plasticité à haute température des solides cristallins (Eyrolles Paris) 1976, p. 132.

[88] Eberhardt, A. and Baudelet, B., J. Microsc. Spectrosc. Electron. 1 (1976) 491.

[89] Baudelet, B., Proceedings of the 4th International Conference on the Strength of Metals and Alloys 1 (1976) 2.

[90] SChMidt-Whitley, R. D., Scripta Met. 8 (1974) 49.

[91] Naziri, H. and Pearce, R., Acta Met. 22 (1974) 1321.

[92] Nuttall, K. and Nicholson, R. B., Phil. Mag. 17 (1968) 1087.

[93] LeE, D., Acta Met. 17 (1969) 1057.

[94] FiKe, K. D. and RaCk, J. J., Trans. A. S. M., 62 (1969) 537.

[95] Lee, E. U. and UNDerwood, E. E., Met. Trans. 1 (1970) 1399.

[96] Alden, T. H., A. S. M. Trans. Quart. 61 (1968) 559.

[97] Friedel, J., Dislocations, Second Edition (Pergamon Press), p. 279 and 315, 1967.

[98] Weertman, J., Rate Processes in Plastic Deformation of Materials. John E. Dorn Symposium (Ed. by J. C. M. Li and A. K. Mukherjee) 1975, p. 315-336. 
[99] JAOUL, B., noted in Ref. [97], p. 315.

[100] Gleiter, H. and Chalmers, B., High Angle Grain Boundaries, Progress in Materials Science (Pergamon Press) 16 (1972), 179.

[101] Biscondi, M., Thesis, Paris (1971).

[102] Lagarde, P. and Biscondi, M., Can. Met. Quart. 13 (1974) 245.

[103] Stevens, R. N., Metal. Rev. 11 (1966) 129.

[104] Bell, R. L., Graeme-Barber, C. and Langdon, T. G., Trans. AIME 239 (1967) 1821.

[105] Ashby, M. F., Surf. Sci. 31 (1972), 498.

[106] Gates, R. S., Acta Met. 21 (1973)-855.

[107] Turner, D. A., Ph. D. Thesis, London (1963).

[108] Baudelet, B., Suery, M. and Eberhardt, A., J. Physique Colloq. 36 (1975) C4-281.

[109] Eberhardt, A. and Baudelet, B., J. Mat. Sci. Lett. 9 (1974) 865.

[110] Cagnon, M., Suery, M., Eberhardt, A. and BaudeLET, B. Acta Met. 25 (1977) 71.

[111] Eberhardt, A., Suery, M. and Baudelet, B., Proceedings of the 4th International Conference on the Strength of Metals and Alloys 1 (1976) 388.
[112] Suery, M., Thesis Metz (1974).

[113] Cutler, C. P., Edington, J. W., Kallend, J. S. and Melton, K. N., Acta Met. 22 (1974) 665.

[114] Dingley, D. J., Proc. 3rd Annual Scanning Electron Microscope Symposium, (1970) 329.

[115] Naziri, H., Pearce, R., Henderson Brown, M. and Hale, K. F., J. Microscopy 97 (1973) 229.

[116] Matsiki, K., Morita, H., Yamada, M. and Murakami Y., Met. Sci. 5 (1977) 156.

[117] LeE, D., Met. Trans. 1 (1970) 309.

[118] Sherby, O. D., Walser, B., Young, C. M. and Cady, E. M., Scripta Met. 9 (1975) 569.

[119] Schadler, H. W., Trans. Met. Soc. AIME 242 (1968) 1281.

[120] Humphries, C. W. and Ridley, N., J. Mat. Sci. 9 (1974) 1429.

[121] Yuasa, E., Kawamura, C. and Morooka, T., J. Japan. Soc. Techn. Plasticity 16 (1975) 935.

[122] Sмith, J. J. and Wood, J. D., Acta Met. 16 (1968) 1219.

[123] Ragab, A. R. and Baudelet, B., Revue Phys. Appl. 12 (1977) 15. 